\title{
A Selected Operational History of the Internal Thermal Control System (ITCS) for International Space Station (ISS)
}

\author{
Vipul P. Patel, Dale Winton \\ Honeywell International \\ Thomas H. Ibarra \\ Boeing
}

\begin{abstract}
The Internal Thermal Control System (ITCS) has been developed jointly by Boeing Corporation, Huntsville, Alabama and Honeywell Engines \& Systems, Torrance, California to meet the internal thermal control needs for the International Space Station (ISS). The ITCS provides heat removal for the critical life support systems and thermal conditioning for numerous experiment racks. The ITCS will be fitted on a number of modules on the ISS. The first US Element containing the ITCS, Node 1, was launched in December 1998. Since Node 1 does not contain a pump to circulate the fluid it was not filled with ITCS fluid until after the US Laboratory Module was installed. The second US Element module, US Laboratory Module, which contains the pumps and all the major ITCS control hardware, was launched in February 2001. The third US Element containing the ITCS, the US Airlock, was launched in July 2001.
\end{abstract}

The dual loop system of the ITCS is comprised of a lowtemperature loop (LTL) and a moderate-temperature loop (MTL). Each loop has a pump package assembly (PPA), a system flow control assembly (SFCA), a threeway mixing valve (TWMV), several rack flow control assemblies (RFCA), cold plates, pressure sensors, temperature sensors, pump bypass assembly (PBA) and a heat exchanger. In addition, the MTL has an additional TWMV, a payload regeneration heat exchanger (P/RHE) and a manual flow control valve (MFCV). The LTL has a service performance and checkout unit (SPCU) heat exchanger. The two loops are linked via one loop crossover assembly (LCA) providing cross loop capabilities and a single PPA, two-loop functionality.

One important parameter monitored by the ground stations and on-orbit is the amount of fluid leakage from the ITCS. ISS fluid leakage is of importance since ITCS fluid is costly to re-supply, may be difficult to clean up in zero-g, and if uncontained could lead to equipment failures and potential hazards. This paper examines the nominal leakage observed over period of a year of on- orbit operation and compares this with analysis predictions. This paper also addresses the off-nominal leakage and a fluid transfer event causing significant changes in accumulator quantity.

\section{INTRODUCTION}

The ITCS provides heat removal for critical life support systems, avionics cooling, and experiment heat loads. It is comprised of pumps, valves, heat exchangers, coldplates and sensors. The system contains an LTL and a MTL. These single-phase, pumped-coolant loops absorb waste heat from subsystems and other equipment and transport the heat outside the pressurized module. There the loops interface with LTL and MTL heat exchangers where the waste heat is rejected to the External Active Thermal Control System (EATCS). The EATCS rejects the heat to space via the thermal radiators.

The U S Element ITCS loops currently on-orbit are the Laboratory (USL) module, Node 1 and Airlock Module. The Lab ITCS contains dual loops of interconnected plumbing, see Figure 1, that service redundant life critical subsystems which include command and control, power and data equipment.

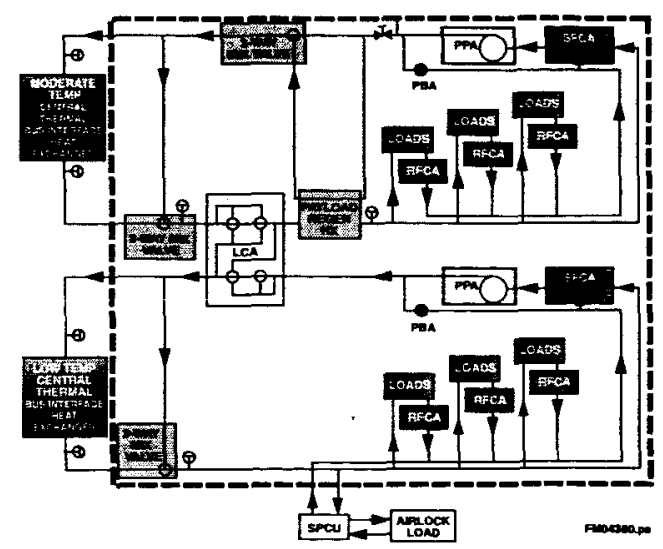

Figure 1. Two Loop System Schematic 
The dual-loop configuration normally operates in an isolated mode with one pump per loop. Isolation valves provide the capability of operating in the isolated mode or to operate both loops with a single common pump in the cross-connected mode. Node 1 has no independent pumping capability, and the ITCS consists mainly of fluid lines that pass through from the Lab or Node 3 to the airlock. Node 2 contains low- and moderatetemperature loops, but they always operate separately. This paper will deal mainly with the US Laboratory module.

\section{ISS US LAB ITCS AND COMPONENTS}

The U.S. Laboratory module ITCS provides the means for transporting thermal energy from the rack to the water-ammonia interface heat exchangers. The ITCS is comprised of two separate water cooling loops: one LTL and one MTL. These loops can be operated separately or cross-connected to provide redundancy in case of a failure of one of the pumps.

\section{COMPONENTS OF THE ITCS}

Pump Package Assembly - The PPA, shown in Figure 2 , is designed to provide coolant pumping, gas removal and coolant filtration. The PPA is made up of the pump assembly, gas trap and filter assembly. An accumulator, located downstream of the gas trap provides fluid reservoir capacity and accommodates fluid expansion and contraction caused by thermal fluctuations. A quantity sensor measures the coolant volume within the accumulator and reports it to the MDM.

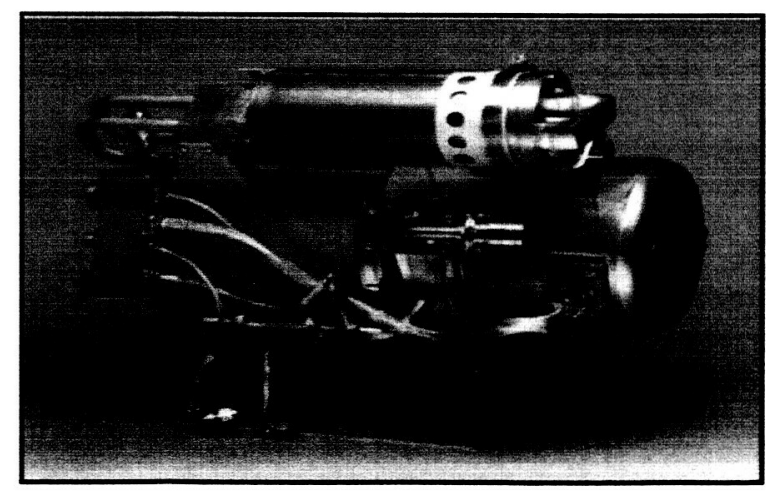

Figure 2. Pump Package Assembly (PPA)

Pump Bypass Assembly - The pump bypass assembly (PBA) shown in Figure 3 is a check valve designed to permit coolant flow in one direction. Coolant flows through the PBA when the ITCS loops are operating in a series, in a cross-connected mode, in order to bypass the nonoperating PPA.

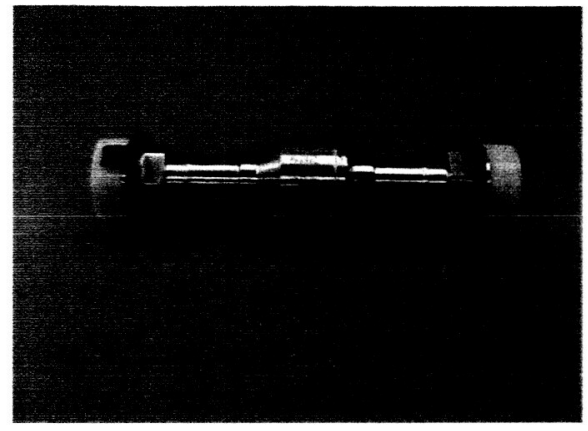

Figure 3. Pump Baypass Assembly (PBA)

Loop Crossover Assembly - The LCA provides isolation between the LTL and MTL in the USL module and allows series operation in the event of a pump failure in either the LTL or MTL. The unit is shown in Figure 5.

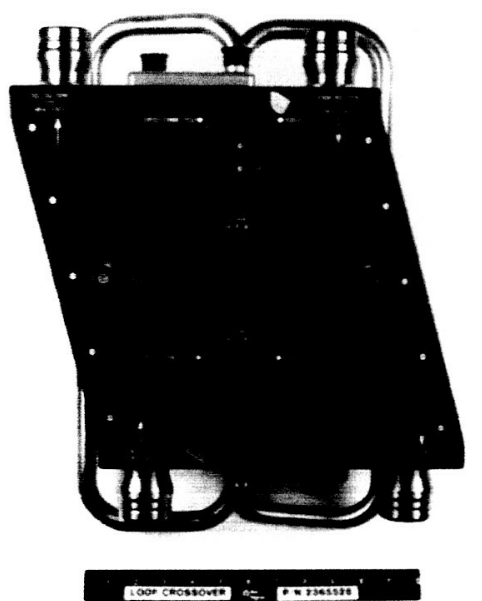

Figure 4. Loop Crossover Assembly (LCA)

Three-Way Mixing Valve - The TWMV is shown in Figure 5. This assembly controls and mixes two coolant flows, from various heat loads, which enter through ports $A$ and $B$. The valve continuously varies and blends the flows, as needed, and delivers the mixtures to the ITCS through the valve outlet port.

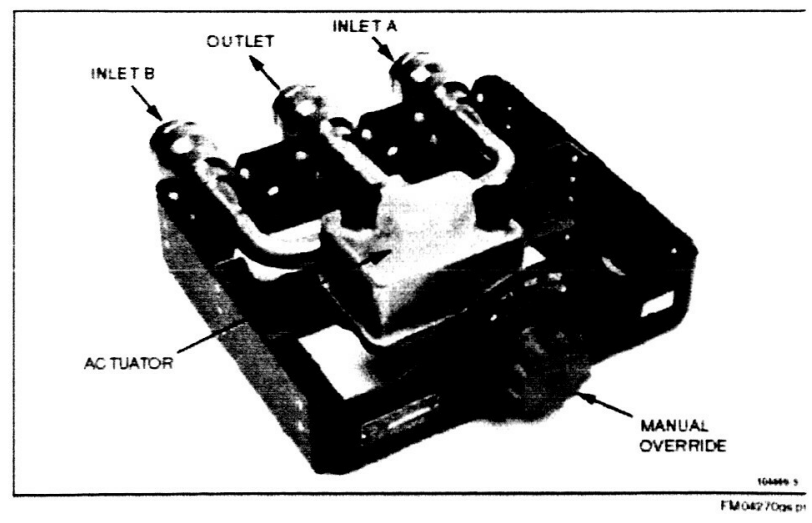

Figure 5. Three-Way Mixing Valve (TWMV) 
System Flow Control Assembly - The SFCA is shown in Figure 6. This assembly provides for proper coolant pressure at various locations in the ITCS and for pump isolation capability.

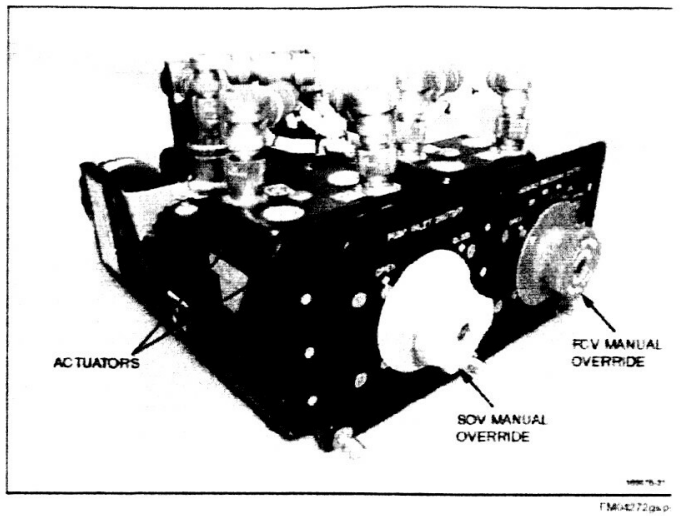

Figure 6. System Flow Control Assembly (SFCA)

Rack Flow Control Assembly - The RFCA, shown in Figure 7, is used to modulate the flow to the user heat loads. Each rack that requires active coolant flow modulation is provided with an RFCA.

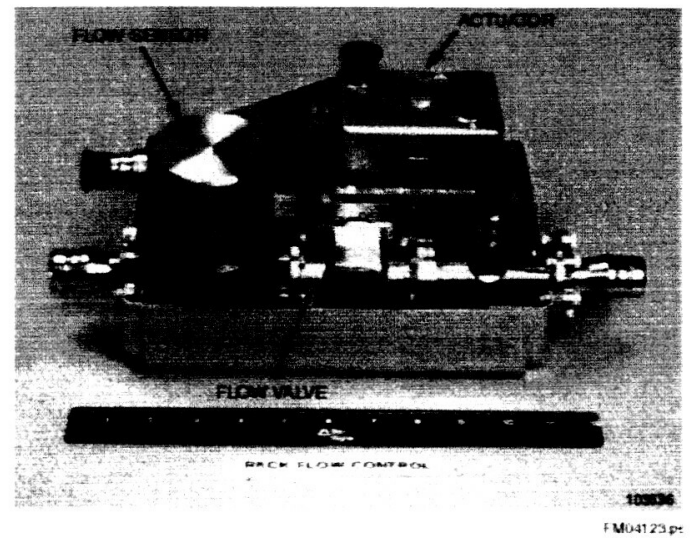

Figure 7. Rack Flow Control Assembly (RFCA)

Manual Flow Control Assembly - The manual flow control valve (MFCV) is shown in Figure 8 . The MFCV provides a means of manually regulating water flow at various places within the low- and moderatetemperature ITCS loops of the ISS.

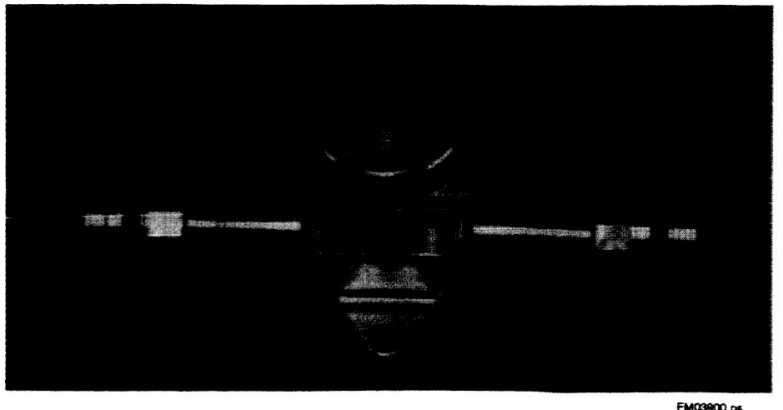

Figure 8. Manual Flow Control Valve (MFCV)
Coid Plates - The ISS ITCS utilizes eight different sizes of cold plates, shown in Figure 9. The cold plates are designed to remove heat at a rate commensurate with design point performance.

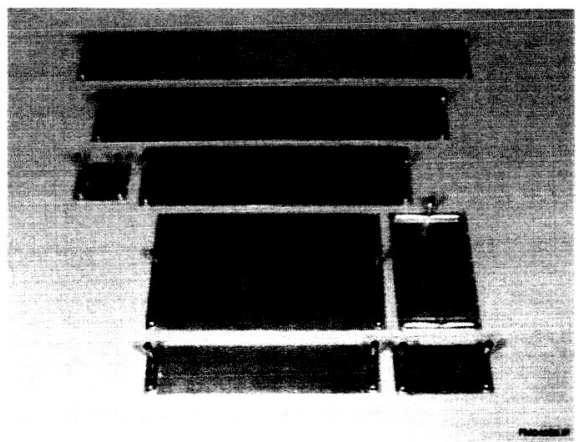

Figure 9. Cold Plates

Payload/Regenerative Heat Exchanger - The Payload/Regenerative Heat Exchanger (P/RHE) is shown in Figure 10. It is used as a regenerative heat exchanger or as a payload isolation heat exchanger, depending on its location within the ITCS. Each side of the heat exchanger accommodates single-loop liquid flow.

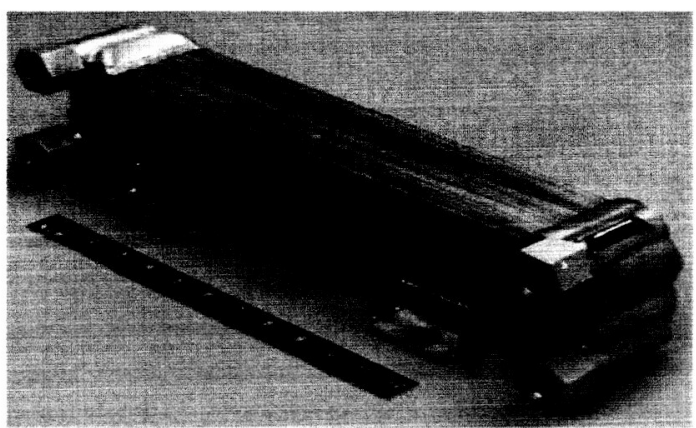

Figure 10. Payload/Regenerative Heat Exchanger (P/RHE)

Service Performance Checkout Unit Heat Exchanger - The service performance and checkout unit (SPCU) heat exchanger, shown in Figure 11, collects heat from the extravehicular mobility unit (EMU) water loops and, through a liquid-to-liquid interchange, transfers heat to the low-temperature ITCS water loop.

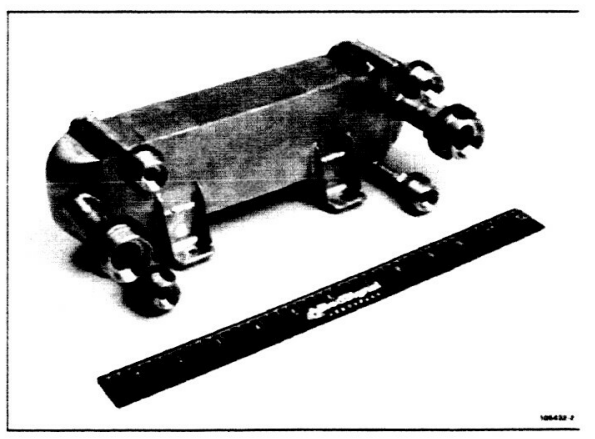

Figure 11. SPCU Heat Exchanger 
Controls (MDM Interface) - For purposes of monitoring systems within the US Destiny Lab, MDM units are used. One of the MDM's in the Lab is used to control the ITCS system components. Leak detection of the ITCS is accomplished through use of component level sensors to detect changes in the quantity of the ITCS fluid. The MDM uses the PPA quantity sensor to measure the change in volume of the ITCS fluid. When the change in fluid quantity passes certain pre-set limits a warning is provided to the ground monitoring station (Mission Evaluation Room) at Johnson Space Center (JSC), Houston, Texas. Automated software is also provided on-orbit to automatically reconfigure the ITCS loops in the event of a large leak to limit the loss of fluid to one gallon or less.

\section{REQUIREMENTS, ANALYSIS AND TESTING}

Fluid Leakage Requirements - The overall system fluid leakage requirement for the ITCS is $0.8 \mathrm{cc} / \mathrm{hr}$ per loop. Since there are two loops in the ITCS the total leakage for the US Laboratory module is $1.6 \mathrm{cc} / \mathrm{hr}$.

In order to satisfy this requirement, each component in the system was required to meet a certain leakage requirement. Since it is difficult to test for water leakage directly the component leakage requirement was specified as a gaseous leakage quantity and this amount of leakage was then converted to water leak rate. Also since ITCS is comprised of a variety of different components (e.g., pumps, valves, coldplates, heat exchangers, hardlines, flex hoses, fittings, etc.), different gaseous specifications are used for each of the major components.

Flex hoses were treated differently from other items. Since the majority of the ITCS flex hoses are made of Teflon and are permeable to gases, a gaseous leak rate specification in Nitrogen or Helium could not be used. Instead the flex hoses were extensively tested to obtain the amount of leakage per unit length and the total leak rate was added to total calculated leak rate for the system. The leakage rate through effusion for the R2678 Teflon hose that was determined through testing was:

\section{X10-3 GM H20/DAY-FOOT.}

Table 1 shows the specified allowable leakage for each of major components comprising the ITCS.

Due to the lack of data on leakage (effusion) from Teflon flex hoses no specification was established for the flex hoses. Rather, the amount of leakage determined through testing and it was assumed that purposes of controlling and monitoring systems within the US Destiny Lab, MDM units are used.

\section{Table 1}

ITCS Component Fluid Specifications

\begin{tabular}{|c|c|c|}
\hline Component & $\begin{array}{c}\text { No. of } \\
\text { components }\end{array}$ & $\begin{array}{c}\text { Specified Leak rate in } \\
\text { stated units }\end{array}$ \\
\hline CDRA & 1 & $30 \mathrm{scc} / \mathrm{hr}$. N2 at $85 \mathrm{psia}$ \\
\hline PPA (2X) & 2 & $\begin{array}{l}5.5 \times 10-3 \mathrm{scc} / \mathrm{sec} \text { N2 } \\
100 \text { psia }\end{array}$ \\
\hline SFCA (2X) & 2 & $\begin{array}{l}1 . X 10-3 \mathrm{scc} / \mathrm{sec} \text { N2 } \\
100 \text { psia }\end{array}$ \\
\hline Pump Bypass CV (2X) & 2 & $\begin{array}{l}1 . X 10-5 \mathrm{scc} / \mathrm{sec} \mathrm{N} 2 \\
100 \mathrm{psia}\end{array}$ \\
\hline TWMV (regen) & 1 & $\begin{array}{l}5 . X 10-4 \mathrm{scc} / \mathrm{sec} \text { N2 } \\
100 \text { psia }\end{array}$ \\
\hline TWMV (CTB) & 2 & $\begin{array}{l}5 . X 10-4 \mathrm{scc} / \mathrm{sec} \text { N2 } \\
100 \mathrm{psia}\end{array}$ \\
\hline LCA & 1 & $\begin{array}{l}1 \times 10-3 \mathrm{scc} / \mathrm{sec} \text { N2 @ } \\
100 \mathrm{psia}\end{array}$ \\
\hline MFCVs (11x) & 11 & $\begin{array}{l}5 . X 10-4 \mathrm{scc} / \mathrm{sec} \text { N2 } \\
100 \mathrm{psia}\end{array}$ \\
\hline RFCA's (15X) & 15 & $\begin{array}{l}7 . X 10-4 \mathrm{scc} / \mathrm{sec} \mathrm{N} 2 @ \\
100 \mathrm{psia}\end{array}$ \\
\hline Flexhoses in Standoffs & & $\begin{array}{l}1.25 \times 10-4 \mathrm{cc} / \mathrm{hr}-\mathrm{ft} \mathrm{H} 20 \\
\text { (for } 1 / 2 \text { " hose) }\end{array}$ \\
\hline
\end{tabular}

Fluid Leakage Analysis - There are various types of leakage paths within the ITCS (e.g., sharp edged orifice or long torturous path). The leak path around hard seals of Gamah fittings and fluid disconnects is mostly of the orifice type, whereas the around gaskets or seals the leak path is probably of the long torturous type as might be seen in the pump package assembly seals. Neverheless, a comparison of both types of leakage was considered using the orifice flow and viscous (Poiseuille) flow equations.

Per Reference (6), the flow through a square-edged orifice is given by:

$Q=Y C A(2 G(144) d P / W) E 0.5$

Where: $Q=$ flow, cubic tt/sec

$\mathrm{Y}=$ Compressibiity factor

$\mathrm{C}=$ Discharge coefficient

$\mathrm{G}=$ gravitational accelertion, $32.2 \mathrm{ft} / \mathrm{sec}$

$\mathrm{DP}=$ pressure differential, psid

$\mathrm{W}=$ weight density, $\mathrm{lb} / \mathrm{cu} \mathrm{ft}$

$A=$ flow area, sq. ft

After simplifying terms and rearranging the equation is:

$q(g)=q(I) Y(w l) / w(g) E 0.5$ (P1/P2)

Where: $w(\mathrm{~h} 20)=62.4 \mathrm{lbm} / \mathrm{cu} . \mathrm{ft}$.

$W(\mathrm{He})=0.0103 \mathrm{lbm} / \mathrm{cu} . \mathrm{ft} @ 14.7 \mathrm{psia}$

$=0.0804 \mathrm{lbm} / \mathrm{cu} . \mathrm{ft}$. $114.7 \mathrm{psia}$

$\mathrm{Y}=0.6$ for shock flow through and orifice

$\mathrm{RC}(\mathrm{He})=0.5$ 
Substituting $P 1=114.7$ psia, $P 2=14.7$ psia and $q(I)=.8$ $\mathrm{cc} / \mathrm{hr}$ and converting $\mathrm{scc} / \mathrm{sec}$ the equivalent gaseous leak rate is:

\section{$Q(\mathrm{He})=\underline{2.2 E^{-2} \mathrm{sec} \mathrm{He} / \mathrm{sec}}$}

Considering viscous (Poiseuille) flow, the equation for gaseous to liquid leakage simplifies to

$\mathrm{Q}(\mathrm{g})=\frac{(\mathrm{P} 1) \mathrm{E} 2-(\mathrm{P} 2) \mathrm{E} 2 \times \mathrm{xu}(\mathrm{l})}{29.4 \times(\mathrm{P} 12-\mathrm{P} 2) \times \mathrm{u}(\mathrm{g})}$

$\mathrm{u}(\mathrm{l})=2.71 \mathrm{lbm} / \mathrm{hr} \mathrm{ft}$

$\mathrm{u}(\mathrm{g})=0.048 \mathrm{lbm} / \mathrm{hr} \mathrm{ft}$
Using these values, plus $P 1=114.7$ psia, $P 2=14.7$ psia, and $q(l)=.8 \mathrm{cc} / \mathrm{hr} \mathrm{H} 20 / \mathrm{sec}$ we get:

$Q(\mathrm{He})=1.6 \mathrm{scc} \mathrm{He} / \mathrm{sec}$.

Since the type of leak path is likely to be a combination of orifice type and viscous type it was concluded that all leak paths were assumed to be orifice type since this is the most conservative assumption.

Using the conversion $0.8 \mathrm{cc} H 20 / \mathrm{hr}=2.2 \mathrm{E}-2 \mathrm{scc}$ $\mathrm{He} / \mathrm{sec}$. for gaseous to water leakage, the total leakage for the U.S. Laboratory module can be calculated as shown in Table 2.

Table 2

U.S. Laboratory Module Predicted Fluid Leakage Rate.

\begin{tabular}{|c|c|c|c|c|c|c|c|c|c|}
\hline Component & $\begin{array}{l}\text { No of } \\
\text { Comp }\end{array}$ & $\begin{array}{l}\text { Spec Leakage in } \\
\text { stated Units }\end{array}$ & $\begin{array}{l}\text { Leak rate in N2 } \\
\text { (scc/sec) }\end{array}$ & $\begin{array}{l}\text { Leak rate in } \\
\mathrm{He}(\mathrm{scc} / \mathrm{sec})\end{array}$ & $\begin{array}{l}\text { Flexhose } \\
\text { Length (ft) } \\
\text { for } 1 / 2^{-1} \text { dia } \\
\text { flexhose }\end{array}$ & $\begin{array}{c}\text { Flexhose } \\
\text { length (ft) } \\
\text { for } 1.0 \text { dia } \\
\text { fiexhose }\end{array}$ & $\begin{array}{l}\text { H20 Leak rate } \\
\text { (cc/hr) at MDP }\end{array}$ & $\begin{array}{l}\text { H20 Leak rate } \\
\text { (cc/hr) at } \\
\text { Nom. Press. }\end{array}$ & $\begin{array}{c}\text { Component } \\
\text { Pressure } \\
\text { (psia) }\end{array}$ \\
\hline CDRA & 1 & $\begin{array}{l}30 \text { scc/hr. N2 at } 85 \\
\text { psia }\end{array}$ & 8.33E-03 & 0.00833 & & & 0.303 & 0.222 & 62.3 \\
\hline PPA (2X) & 2 & $\begin{array}{l}5.5 \times 10-3 \mathrm{scc} / \mathrm{sec} \\
\text { N2@100 psia }\end{array}$ & $5.50 E-03$ & 0.0055 & & & 0.400 & 0.313 & 26 to 90 \\
\hline SFCA $(2 X)$ & 2 & $\begin{array}{l}1 \times 10-3 \mathrm{scc} / \mathrm{sec} \mathrm{N2} \\
\text { @100 psia }\end{array}$ & $1.00 E-03$ & 0.001 & & & 0.073 & 0.038 & 52.3 \\
\hline $\begin{array}{l}\text { Pump Bypass } \\
\text { CV }(2 X)\end{array}$ & 2 & $\begin{array}{l}\text { 1.X10-5 scc/sec N2 } \\
@ 100 \text { psia }\end{array}$ & $1.00 E-05$ & 0.00001 & & & 0.001 & 0.001 & 69.7 \\
\hline $\begin{array}{l}\text { TWMV (regen) } \\
\text { TWMV (CTB) }\end{array}$ & $\begin{array}{l}1 \\
2\end{array}$ & $\begin{array}{l}5 . \times 10-4 \mathrm{scc} / \mathrm{sec} \mathrm{N} 2 \\
@ 100 \mathrm{psia} \\
5 . \times 10-4 \mathrm{scc} / \mathrm{sec} \mathrm{N} 2 \\
@ 100 \mathrm{psia}\end{array}$ & $\begin{array}{l}5.00 \mathrm{E}-04 \\
5.00 \mathrm{E}-04\end{array}$ & $\begin{array}{l}0.0005 \\
0.0005\end{array}$ & & & $\begin{array}{l}0.018 \\
0.036\end{array}$ & $\begin{array}{l}0.013 \\
0.024\end{array}$ & $\begin{array}{l}69.7 \\
66.7\end{array}$ \\
\hline LCA & 1 & $\begin{array}{l}1 \times 10-3 \text { scc/sec N2 } \\
\text { @ } 100 \text { psia }\end{array}$ & $1.00 E-03$ & 0.001 & & & 0.073 & 0.049 & 66.7 \\
\hline MFCVs (11x) & 11 & $\begin{array}{l}5 \times 10-4 \mathrm{scc} / \mathrm{sec} \mathrm{NZ} \\
@ 100 \mathrm{psia}\end{array}$ & $5.00 E-04$ & 0.0005 & & & 0.200 & 0.105 & 52.3 \\
\hline RFCAs (15X) & 15 & $\begin{array}{l}7 . \times 10-4 \mathrm{scc} / \mathrm{sec} \mathrm{N} 2 \\
@ 100 \mathrm{psia}\end{array}$ & $7.00 E-04$ & 0.0007 & & & 0.382 & 0.200 & 52.3 \\
\hline $\begin{array}{l}\text { Fiexhoses in } \\
\text { Standoffs }\end{array}$ & & $\begin{array}{l}1.25 \times 10-4 \mathrm{cc} / \mathrm{hr}-\mathrm{ft} \\
\mathrm{H} 20 \text { (for } 1 / 2^{-} \text {hose) }\end{array}$ & na & na & 282 & 30 & 0.043 & 0.043 & \\
\hline $\begin{array}{l}\text { Fiexhoses in } \\
\text { Endcones }\end{array}$ & & $\begin{array}{l}1.25 \times 10-4 \mathrm{cc} / \mathrm{hr}-\mathrm{ft} \\
\mathrm{H} 20 \text { (for } 1 / 2 \text { "hose) }\end{array}$ & na & na & 155 & 80 & 0.039 & 0.039 & \\
\hline $\begin{array}{l}\text { Flexhoses in all } \\
\text { subsystem racks }\end{array}$ & & $\begin{array}{l}1.25 \times 10-4 \text { cchr-ft } \\
\text { H2O (for } 1 / 2 \text { hose) }\end{array}$ & na & na & 206 & 81 & 0.046 & 0.046 & \\
\hline Fittings and QDs & & $1 \times 10-4 \mathrm{scc} / \mathrm{sec} \mathrm{He}$ & $1.00 E-04$ & $1.00 E-04$ & & & 0.036 & 0.025 & 69.7 \\
\hline Total Lab & & $0.8 \mathrm{cc} / \mathrm{hr} \mathrm{H} 20$ & & & & & 1.650 & 1.116 & \\
\hline
\end{tabular}

Based on spec gaseous leak rates converted to a water leak rate at the MDP of 100 psia, the total calculated lab leakage rate is:

\section{$1.65 \mathrm{cc} / \mathrm{hr}$ for both loops.}

Leakage rates calculated using the above method can be reduced by taking into consideration the actual component pressure within the system. Taking this into consideration, the total Lab leakage rate is:

\section{$1.12 \mathrm{cc} / \mathrm{hr}$ for both loops.}

This calculated leakage can be further reduced by taking into consideration the "zero leakage" point. Below a certain gaseous leak rate, water will not leak. The zero water leakage rate range is between $1 \mathrm{E}-3$ to $1 \mathrm{E}-4$ $\mathrm{scc} / \mathrm{sec}$ of Helium.

In order to retain a comfortable measure of conservatism the "zero leak" limit was not employed during the verification of Lab leakage requirements. Further refinements and consideration of hoses for payloads resulted in a total calculated total Lab leakage rate of:

\section{$1.41 \mathrm{cc} / \mathrm{hr}$ for both loops.}


In the next section the predicted leakage quantity is compared with the actual on-orbit leakage and leakage specifications.

Fluid Leakage On-orbit Data - Fluid quantities are one of the many parameters monitored by the Mission Support Room in Houston, Texas. The accumulator quantity sensor located in the Low- and Moderatetemperature pump package assemblies provides a realtime means of determining ITCS fluid quantity and provides and means for assessing leakage. The accumulator quantities for the low- and moderatetemperature loops are shown in Figure 12 and Figure 13 , respectively, for a period of approximately one year.

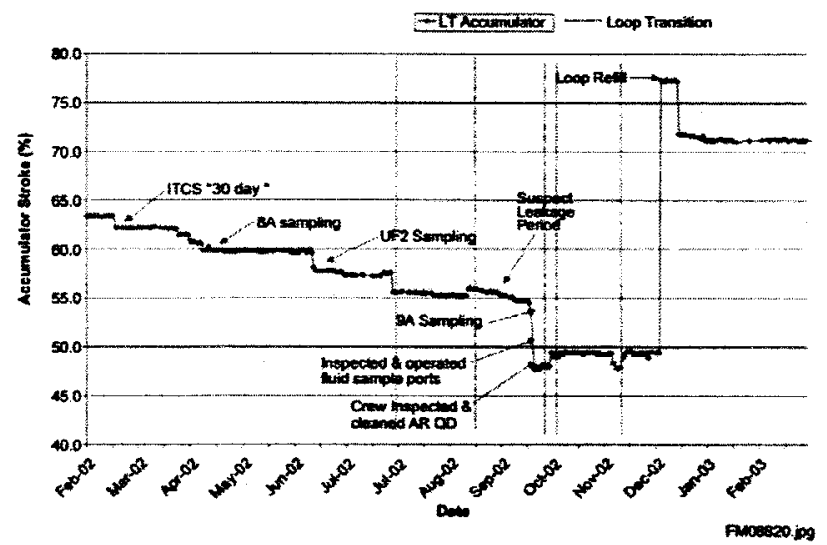

Figure 12. Low-Temperature Accumulator Quantity

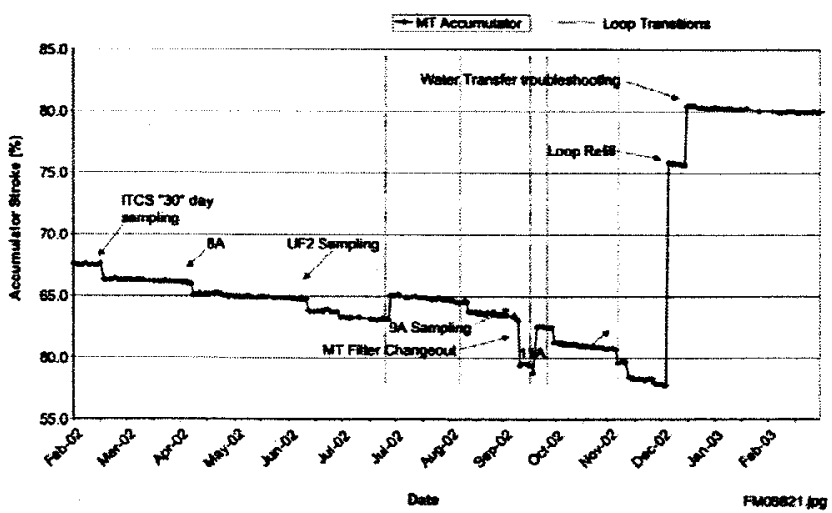

Figure 13. Moderate-Temperature Accumulator Quantity

As can be seen in Figure 12 and Figure 13, there are several events (e.g. sampling, transitions, refills, etc.) that cause the accumulator quantities to change abruptly. However, some of these events are not considered leakages since the fluid is either contained (as in the case of sampling) or transferred from one loop to the other (as in the case of transitions). In order to assess nominal system leakage these quantities must be factored out since they affect the accumulator quantities but are not actually leakages.
A special case of leakage is where an abrupt change in rate of fluid loss takes place which represents an actual small leak not large enough to trigger the automatic leak detection software (known as LRITCS) but larger than the normal background system leakage. There have been two such events on-orbit to date. While these leakages represented a noticeable change in slope of leakage quantities, in neither case did these leakages exceed applicable leak specifications. However, since the normal leak is so small (less than $1 \%$ per month), even a small leak that doesnot exceed the spec leak rate of $0.8 \mathrm{cc} / \mathrm{sec}$ produces a noticeable accelerated trend. These two off-nominal leakage events will be discussed in more detail in the next section.

After removing the abrupt changes in fluid volume, the normal leakage for each system was determined. The cumulative normal leakage rates for the low- and moderate-temperature loop is shown in Figure 14 and Figure 15, respectively.

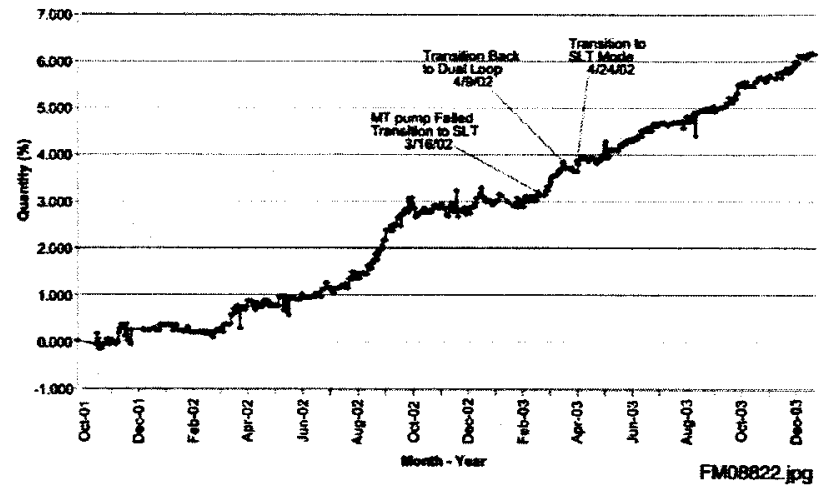

Figure 14. Low-Temperature Loop Cumulative Normal System Leakage

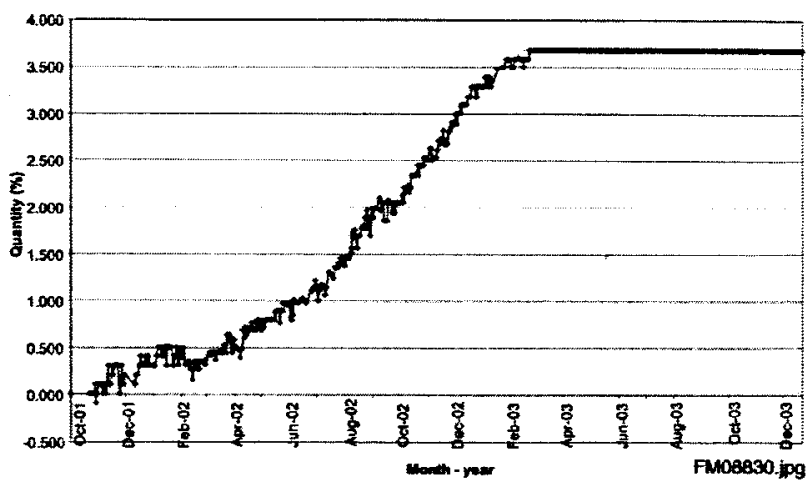

Figure 15. Moderate-Temperature Loop Cumulative Normal System Leakage

As can been seen in Figure 14, the low-temperature cumulative leakage quantity is not as smooth as the moderate-temperature cumulative leakage. This is partially due to the fact there was a leakage event on the low-temperature loop. This leakage event is indicated 
by the change of slope starting in September of 2002 and lasting for approximately twenty-eight days.

It may also be observed that the moderate-temperature loop cumulative quantity flattens out in mid-March of 2003. This is due to the transition to single low temperature loop mode (LT PPA operating) where the Moderate-temperature PPA is off and the accumulator quantity is no longer in the active fluid loop.

Since the requirement is stated in cc/hr of leakage, the data was gathered and converted to a cc/hr per loop. The conversion for leakage from percent of accumulator quantity is calculated as follows:

\section{Leakage $(\mathrm{cc} / \mathrm{hr})=\%$ Quan $/ 100 \times 650 \mathrm{in}^{3} \times 16.39 \mathrm{cc} / \mathrm{in}{ }^{3}$}

Therefore, $1 \%$ drop in accumulator quantity $=106.5 \mathrm{cc}$.

The calculated accumulator leakage $(\mathrm{cc} / \mathrm{hr})$ is shown in Figure 16 and Figure 17 for the low- and moderatetemperature loops.

Based on the data gathered from Figure 14 through Figure 17, it can be seen that the average leakage rate for the low- and moderate-temperature loops are as follows:

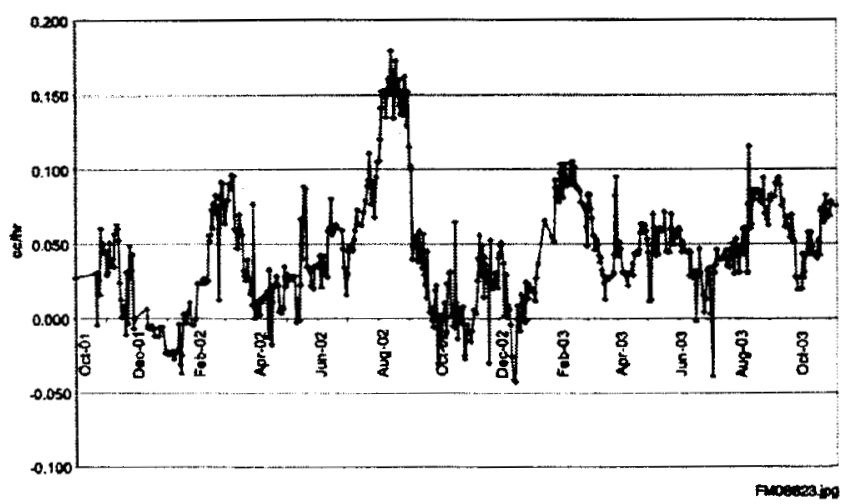

Figure 16. Low-Temperature Accumulator Leak Rate

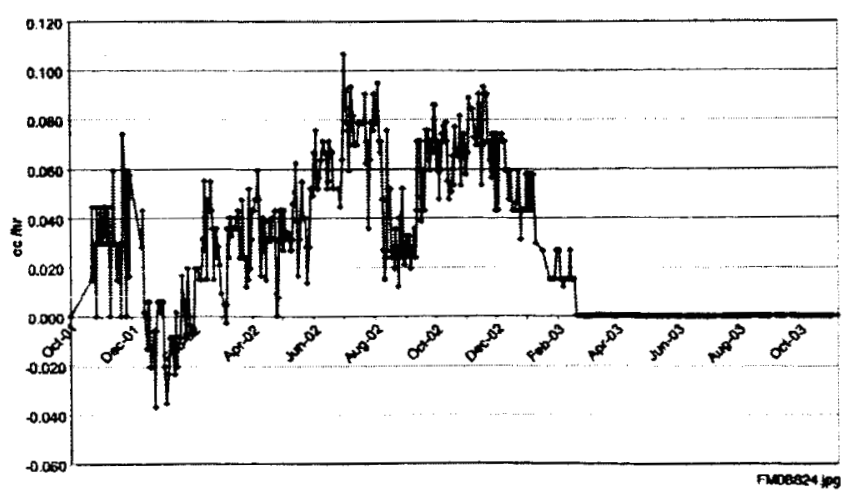

Figure 17. Moderate-Temperature Accumulator Leak Rate
For the low-temperature loop between 1/25/02 and $4 / 25 / 03$, excluding the leakage event in which $1.2 \%$ accumulator quantity was lost (see next section) the leakage rate is,

$\frac{(3.64 \%-1.2 \%-036 \%) / 100 \times 650 \mathrm{in}^{3} \times 16.39 \mathrm{cc} / \mathrm{in}^{3}}{5 \mathrm{mo} \times 30 \text { days } / \mathrm{mo} \times 24 \mathrm{hr} / \text { day }}=.07 \mathrm{cc} / \mathrm{hr}$

For the moderate-temperature loop between 3/10/02 and $3 / 10 / 03$ the leakage rate is,

$\frac{(3.57 \%-0.34 \%) / 100 \times 650 \mathrm{in}^{3} \times 16.39 \mathrm{cc} / \mathrm{in}^{3}}{365 \text { days } \times 24 \mathrm{hr} / \mathrm{day}}=.04 \mathrm{cc} / \mathrm{hr}$

These leak rates are compared to the allowable spec leakage rate of $0.8 \mathrm{cc} / \mathrm{hr}$ per loop. Therefore, the average rate of leakage to date compared to allowable leak rate is 10 to 20 times better than specification, excluding specific leakage events.

\section{ON-ORBIT LEAKAGE EVENTS}

There have been several events that have caused either a gain or loss in accumulator quantities. See Figure 18. Many of these are planned events such as fluid sampling and accumulator refills. In some cases accumulator quantities are affected by planned system operations such as loop transitions where a known quantity of fluid is transferred from one accumulator to the other

In these cases the fluid quantity transfer is expected. In other cases unexpected fluid quantity losses or transfers have occurred. In one such case, an anomaly occurred where a check valve stuck causing ITCS fluid to be transferred from one accumulator to other. This anomaly will be addressed further in this section. In addition, there have been occurrences where accumulator quantities have dropped when installing fluid jumpers during rack re-configurations. In these cases it was found that the fluid jumpers contained a small amount of air causing the accumulator quantities to drop in relation to the amount of air that was contained in the volume. Initially, upon installation, the air was compressed and then later was removed by the gas trap.

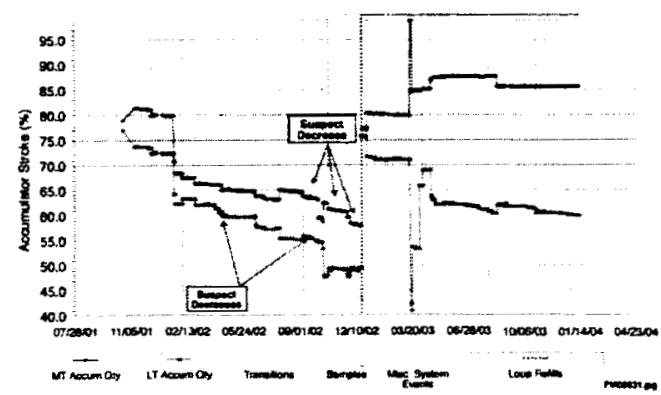

Figure 18. On-Orbit Leakage Events 
Leakage events of the most concern are those where fluid is uncontained in the cabin. These can be large and noticeable to barely detectable but larger than normal. There have been two such leakage events on ISS since the start up of the active fluid loops. The first was of the barely detectible type where there were no obvious visible signs of leakage, but there was a change in the normal accumulator quantity trend. The second event was large enough to be noticeable by the crew and happened while the ITCS was changed from the normal operating configuration to the unmanned configuration. The unmanned configuration was being used because both crewmembers were conducting an EVA with no crewmembers inside the station.

The first on-orbit leakage event -The first leakage event on ISS occurred over a 28-day period ending October 3, 2002. During this period the low-temperature accumulator quantity decreased by $1.2 \%$. This is a relatively small leak (128 cc's) and only slightly larger than the normal leak trend. At the time there were no known actions (i.e. samples, transitions, etc.) that would have caused this accelerated drop in accumulator quantity. Also during this period of time it was observed that the moderate temperature accumulator quantity was decreasing at rate of only $0.3 \%$ per month (subtracting out known quantity transfers).

Although the leak rate seen in the low temperature loop was less than the allowable spec leak rate of $0.8 \mathrm{cc} / \mathrm{hr}$. it was greater than the previous observable trend, and therefore it was investigated.

The candidate leak sources were: (1) leaking from fittings of the sample hardware, (2) leaking quick disconnects, (3) excessive weeping from the gas trap membrane caused from the effect of nickel, (4) a bubble in the system, possibly due to QD ops or nominal PL connections, (5) permeation of water vapor through Teflon hoses, (6) temperature change.

One by one the potential leak sources were analyzed, investigated and ruled out. Since the leak was so small it took several months of trend monitoring to evaluate if there was a real leakage event or perhaps some heretofore unknown characteristic of the system. Figure 19 shows the low-temperature accumulator leakage rate as a percentage of accumulator quantity computed for 30-day intervals. The period of accelerated leakage is clearly shown as a spike occurring in early September of a range up $1.2 \%$ per month.

After months of evaluation only one of the candidate leak sources given above had not been ruled out. Evaluation leakage data indicated that the possible source of the leak was the supply QD's for the atmosphere revitalization (AR) rack. Based on this information the crew took action to inspect and clean the low temperature AR rack QD's. Small evidence of leakage was found, but only after further trend monitoring was it concluded that the action taken by the crew to wipe and clean the mating surfaces of the AR rack QD's actually halted the leak. The root cause of the leakage was therefore attributed to transient foreign object debris (F.O.D.) in the supply side QD's.

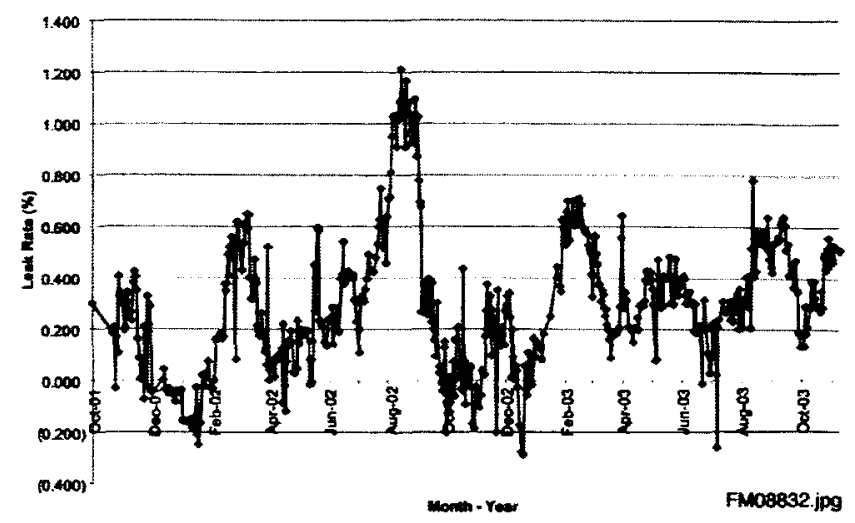

Figure 19. Low-Temp Accumulator Quantity During Leak Event

Based on the trend shown in Figure 19, it was concluded that the normal leakage for the low-temperature loop was less than $1 \%$ per month. Any leakage greater than $1 \%$ would be a signal for the thermal control system (TCS) team to investigate for possible abnormal leakage.

Second on-orbit leakage event - The second leakage event while the ITCS was configured in the unmanned configuration. The ITCS jumpers were in the unmanned configuration from GMT 2004/056/15:00 until 2004/58/23:00. The unmanned configuration is performed to provide a redundant method means of cooling the moderate-temperature loop racks in the event of a leak while the crew is not present. This entails switching the ITCS to dual loop mode and installing jumpers from the low-temperature loop to selected racks to provide redundancy.

While in the unmanned configuration (for approximately 56 hours) the moderate temperature loop decreased approximately $1 \%$. The accumulator quantities of the low and moderate temperature accumulators are shown as Figure 20 and Figure 21 respectively.

While the rack jumpers were we uninstalled the crew observed visible leakage around forward endcone QDs (around $30 \mathrm{ml}$ ) and leakage around a second QD located at the Deck 1 location (around $125 \mathrm{ml}$ ).

The period of leakage can be seen in Figure 21 for the time period from 58:23 to 56:10. Table 3 summarizes the actual water leakage during this time period. 


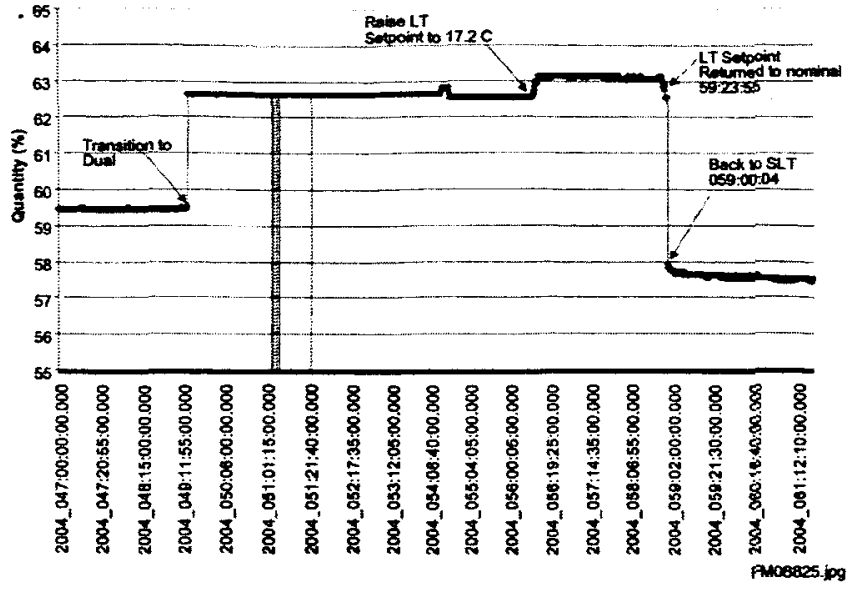

Figure 20. Low-Temperature Accumulator Quantity During Leak Event.

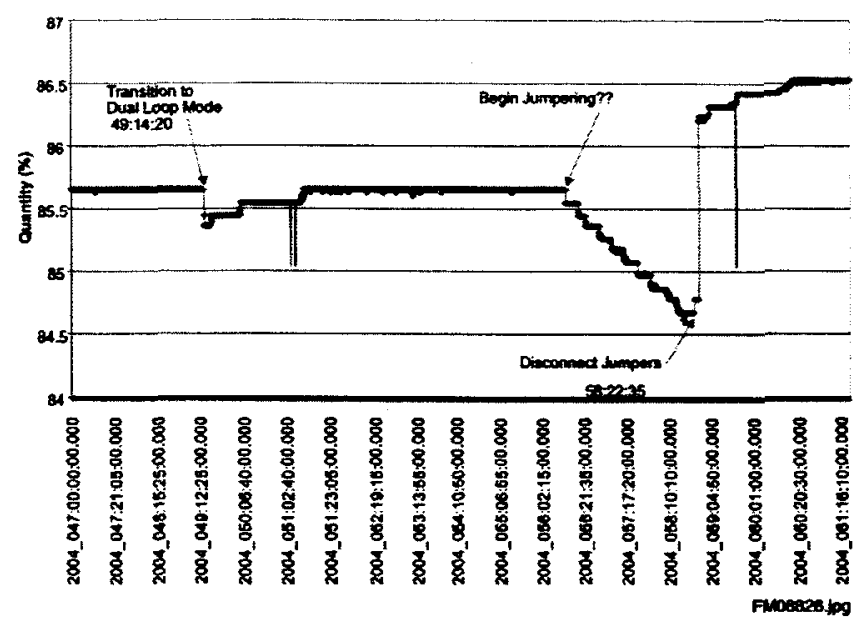

Figure 21. Mod-Temperature Accumulator quantity During Leak Event.

Table 3

ITCS On-Orbit Fluid Leakage Event

\begin{tabular}{|l|l|l|l|}
\hline Event & $\begin{array}{l}\text { LT Accum } \\
\text { Quantity (\%) }\end{array}$ & $\begin{array}{l}\text { MT Accum } \\
\text { Quantity (\%) }\end{array}$ & $\begin{array}{l}\text { Combined Quantity } \\
(\%)\end{array}$ \\
\hline $\begin{array}{l}\text { Before Transition to } \\
\text { Dual Loop } \\
(2 / 18 / 04)\end{array}$ & 59.5 & 85.65 & 145.149 \\
\hline $\begin{array}{l}\text { Begin Jumper to MTL } \\
56: 14: 20\end{array}$ & 62.9 & 85.65 & 149.5 \\
\hline $\begin{array}{l}\text { Disconnect Jumper } \\
\text { to MTL } \\
\text { 58:22:35 }\end{array}$ & 63.14 & 84.67 & 147.81 \\
\hline $\begin{array}{l}\text { After transition back } \\
\text { to Single Loop } \\
\text { (2/27/04) }\end{array}$ & 57.82 & 86.21 & 144.03 \\
\hline Net change & -1.68 & +.56 & $-1.12(119 \mathrm{cc})$ \\
\hline
\end{tabular}

While the crew reported a loss of $175 \mathrm{ml}$, the actual amount of fluid lost was $119 \mathrm{ml}$. Based on the normal leakage of approximately $15 \mathrm{ml}$ expected for this period of time, that actual additional loss of fluid was $104 \mathrm{ml}$.

It was assumed the leakage was a result of Foreign Object Debris (F.O.D.) as occurred in the first incidence of off-nominal leakage. Confirmation of the cause of this leakage will be confirmed after the hardware is returned to the ground and inspected.

Accumulator quantity transfer - sticking check valve - The on-orbit ITCS fluid level in the LTL accumulator was reduced during March, 2003. Simultaneous increase of the MTL fluid level was observed. The cause of this phenomenon is due to reverse leakage of the fluid through the PPA check valve. The reverse leakage allowed the fluid to gather in the MTL accumulator.

Figure 22 shows a schematic diagram of PPA. The check valve is located near the outlet of the PPA, just prior to flow meter. The check valve is designed to regulate the flow towards the outlet direction. A reverse flow through the check valve will result into fluid flowing into the accumulator.

The on-orbit event, where the check valve was stuck open in the MTL loop during single loop operation caused fluid to flow into the MTL accumulator. The LTL accumulator tried to compensate this loss of fluid from the system. As a result, the MTL accumulator fluid quantity went up with simultaneous reduction in LTL fluid quantity. The subject PPA and check valve is still on orbit awaiting return. No direct investigation of the check valve, is now possible.
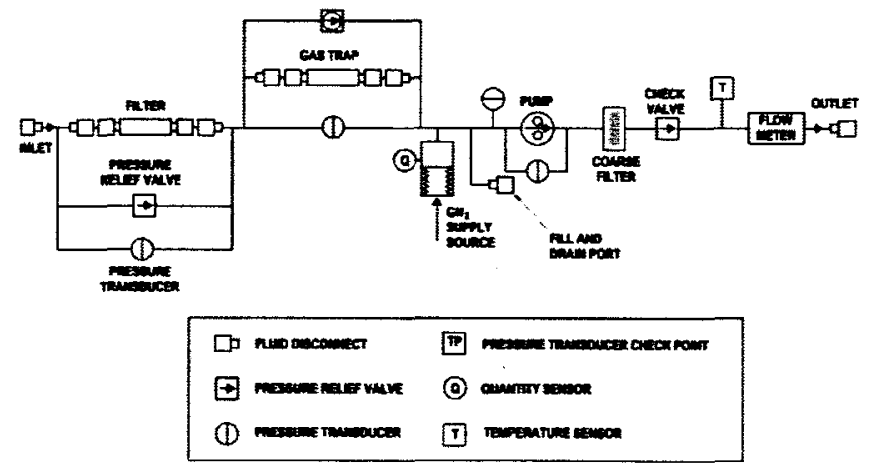

PPA Scomic 
A similar check valve event, where the check valve was stuck open occurred at Honeywell Lab during normal refurbishment of a PPA. The check valve was removed from the PPA and bench tests were conducted unsuccessfully to repeat the failure. See Figure 23.

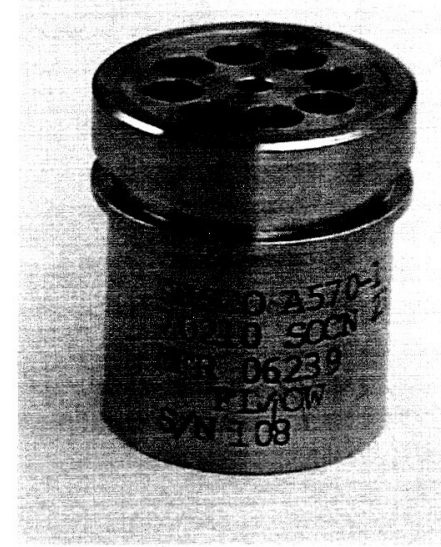

Figure 23. PPA Check Valve

AUSCO Inc. successfully ran Acceptance test at its facility. Upon disassembly of the check valve, a sticky substance (foreign object) was discovered. See Figure 24.

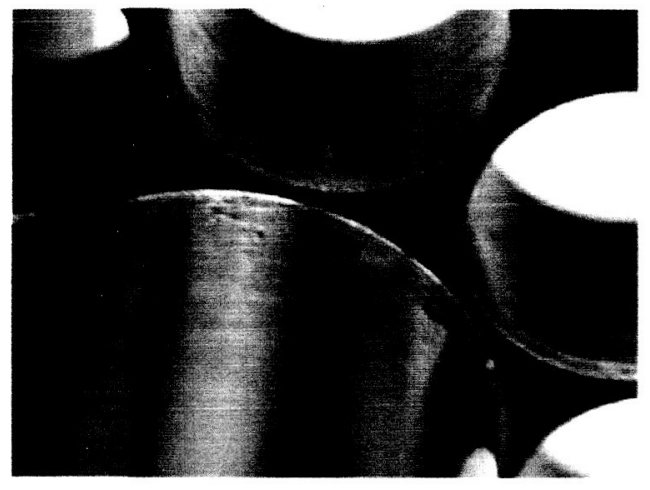

Figure 24. Check Valve Contamination

The substance was analyzed at Boeing Huntsville laboratories and identified as polymeric methacrylate adhesive (Similar to LocTite). The substance was not found on any components upstream or downstream from the check valve, leading to the conclusion that the substance was local to the check valve and, therefore, must have occurred during manufacture of the valve.

Additional unused check-valves from inventory were examined. The valves from inventory were from a second batch of the valves purchased at a later date than the first valve that were disassembled and analyzed. Four valves were examined and no contamination was found.

The design of the check valve was evaluated simultaneously. It was revealed that the centerline of the valve body (with valve seat) and centerline of the guide were eccentric to each other up to .0025 in. The diametrical clearance between the poppet ID and guide $O D$ is .0005 to .001 in. causing a potential gap between the seat and the poppet. (See Figure 25 and Figure 26).

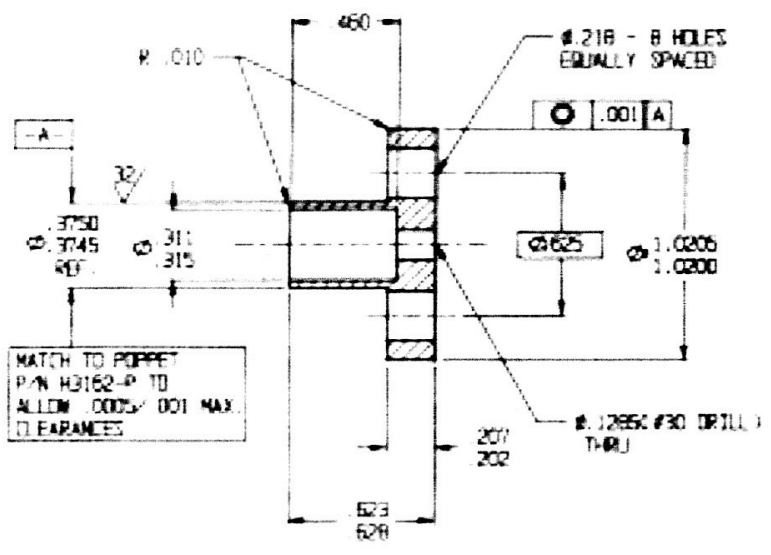

Figure 25. Clearance Between Poppet and Guide

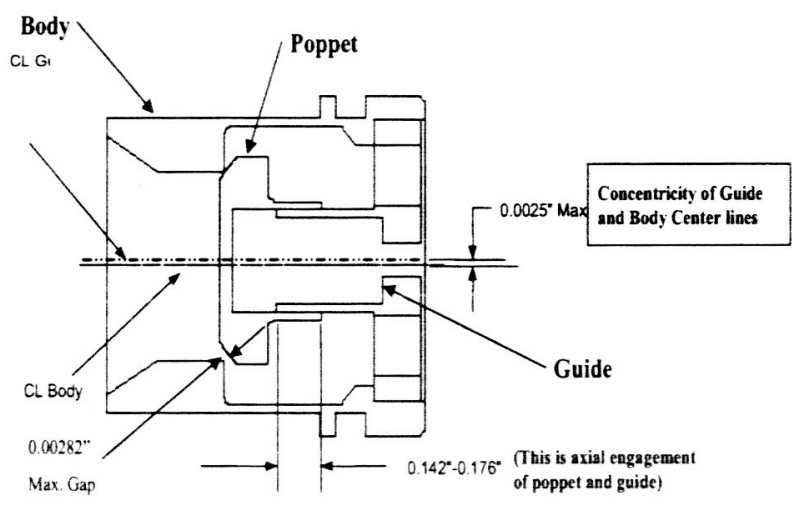

Figure 26. Concentricity Error

The gap was evident during evaluation of the check valve light test (see Figure 27). It is possible that such an opening can occur due to a design problem or contamination or a combination of both.

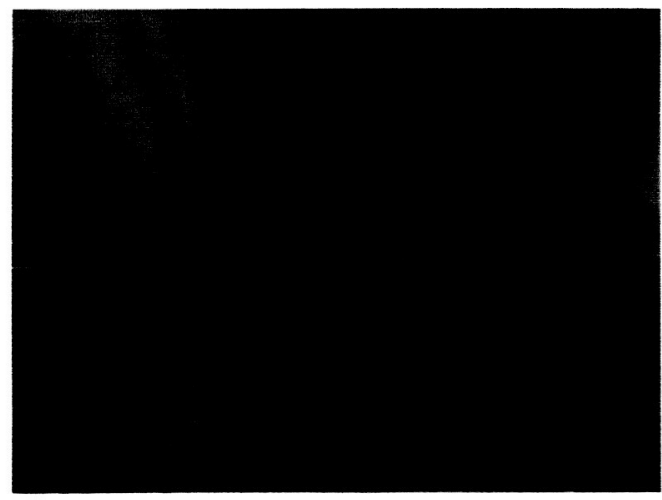

Figure 27. Check Valve Gap 
The approach to fix both of these issues is to take a number of steps.

1. Modify valve design to increase clearance between the poppet ID and guide O.D.

2. Clean and assemble the check valve in a clean room environment

3. Handle check valves with care so that no contamination is introduced.

It is anticipated that after these changes, the check valve should operate normally without any abnormal leakage. The internal contamination should be benign and should have no effect on check valve leakage.

\section{CONCLUSIONS}

The operational experience to date has demonstrated that the ITCS fluid quantities have been managed with minimal impact by ground monitoring and software controls.

The data presented in this report has demonstrated that the nominal leak rate to date is nearly 10 to 20 times better than worse case predictions and 10 to 20 times better than specifications which are based on worse case leakage assumptions.

While there have been occurrences of abnormal leakage, in all cases the leakages have been relatively small and where they are not, have been isolated to one or two known locations.

For the future, the effect of coalescence of particulates in the ITCS remains an area to be closely monitored since it is suspected to be a source of contamination and possible cause of the known leakage events. Therefore, control of particulates in ITCS fluid remains an area where improvements can be made for future fluid systems.

\section{ACKNOWLEDGEMENTS}

This work was funded by NASA Contract NAS15-10000 and Boeing Contract HX2200.

\section{ACRONYMS}

$\begin{array}{ll}\text { C\&DHS } & \text { Command and Data Handling System } \\ \text { EATCS } & \text { External Active Thermal Control System } \\ \text { EMU } & \text { Extravehicular Mobility Unit } \\ \text { EPV } & \text { Eight-Port Valve } \\ \text { FCV } & \text { Flow Control Valve } \\ \text { HAB } & \text { Habitation Module } \\ \text { ISPR } & \text { International Standard Payload Rack } \\ \text { ISS } & \text { International Space Station } \\ \text { IR } & \text { Infrared } \\ \text { ITCS } & \text { Internal Thermal Control System }\end{array}$

$\begin{array}{ll}\text { KSC } & \text { Kennedy Space Center } \\ \text { LCA } & \text { Loop Crossover Assembly } \\ \text { LT } & \text { Low Temperature Loop } \\ \text { MDM } & \text { Multiplexer/Demultiplexer Module } \\ \text { MFCV } & \text { Manual Flow Control Valve } \\ \text { MT } & \text { Moderate Temperature Loop } \\ \text { ORU } & \text { Orbit Replaceable Unit } \\ \text { P/RHE } & \text { Payload/Regenerative Heat Exchanger } \\ \text { PBA } & \text { Pump Bypass Assembly } \\ \text { PPA } & \text { Pump Package Assembly } \\ \text { RFCA } & \text { Rack Flow Control Assembly } \\ \text { SFCA } & \text { System Flow Control Assembly } \\ \text { SOV } & \text { Shut-Off Valve } \\ \text { SPCU } & \text { Service Performance and Checkout Unit } \\ \text { TWMV } & \text { Three-Way Mixing Valve } \\ \text { USL } & \text { United States Laboratory Module }\end{array}$

\section{REFERENCES:}

1. Wentz, Gary L, Jr.: International Space Station Environmental Control and Life Support System Verification and test Program for the United States Laboratory Element, SAE 2000-01-2294, 30th Intemational Conference on Environmental Systems, France

2. Reuter, James L.: International Space Station Environmental Control and Life Support System Status: 1999-2000, 2000-01-2248, 30th International Conference on Environmental Systems, France

3. NASA International Space Station Program, “ Qualification and Acceptance Environmental Test Requirements", SSP 41172 Rev. C.

4. Humphrey, Joseph, T., Laura N. Supra, and Michael B. Faust. A Thermal Control System DualMembrane Gas Trap for the International Space Station, 972410, 27th International Conference on Environmental Systems, Nevada.

5. Ditter, Laura N. and Michael B. Faust. Development of Thermal Control System Dual-Membrane Gas Trap, 9541461, 25th International Conference on Environmental Systems.

6. Patel, Vipul P.; Barrido, Richard; Johnson, Brien; Ibarra, Thomas; Development of the Internal Thermal Control System (ITCS) for International Space Station (ISS); 2001-01-2332, 31" Intemational Conference on Environmental Systems. 